DOI 10.37882/2500-3682.2021.02.18

\title{
АНАЛИЗ ПОКАЗАТЕЛЕЙ САМООТНОШЕНИЯ И НАРЦИССИЗМА, А ТАКЖЕ ОТНОШЕНИЯ К ВЕРЕ КАК ПРЕДИКТОРОВ ЛИЧНОСТНОЙ ЗРЕЛОСТИ-НЕЗРЕЛОСТИ У СОВРЕМЕННОЙ МОЛОДЕЖИ
}

\section{ANALYSIS OF INDICATORS \\ OF SELF-ATTITUDE AND NARCISSISM, AS WELL AS ATTITUDE TO FAITH AS PREDICTORS OF PERSONAL MATURITY- IMMATURITY IN MODERN YOUTH}

A. Machukha

O. Vasilyeva

Summary: The article considers in detail the assessment of personal or psychological maturity as a multi-vector and multi-factor education in specific life manifestations, manifested in the adaptive abilities of the individual to use their non-social personal reserves and in the ability to find the most optimal own «niches» of life presence that benefit other people. Personal maturity is presented as the ability to keep yourself from doing wrong, multiplied by the constant ability to do everything necessary in each specific life situation. As a final measure of personal maturity, an assessment of a person's life line is presented, as well as the ability to show reflection. In the understanding of personal maturity, the main emphasis is placed on the presence of personal properties, qualities and their manifestations of active life involvement, and with a focus on social morality.

Keywords: personal maturity, personal reserves, reflection, motives, selfattitude, narcissism, spirituality, faith, young people.

\author{
Мачуха Александр Михайлович \\ Соискатель, Южный Федеральный Университет \\ aleksandrinfo@bk.ru \\ Васильева Ольга Семеновна \\ К.б.н., профессор, Южный Федеральный Университет \\ vos@sfedu.ru
}

Аннотация: В статье подробно рассмотрена оценка личностной или психологической зрелости как многовекторного и многофакторного образования в конкретных жизненных проявлениях, проявляемой в адаптивных способностях личности задействования своих несоциальных личностных резервов и в умении находить наиболее оптимальные собственные «ниши» жизненного присутствия, приносящие пользу другим людям. Личностная зрелость представлена как умение удерживать себе от делания недолжного, помноженное на постоянное умение делать все необходимое в каждой конкретной жизненной ситуации. В качестве конечной меры личностной зрелости представлена оценка линии жизни человека, а также умение проявлять рефлексию. В понимании личностной зрелости основной акцент ставится на наличие у человека личностных свойств, качеств и их проявлений активной жизненной включенностью, и с ориентацией на социальную нравственность.

Ключевые слова: личностная зрелость, личностные резервы, рефлексия, м0тивы, самоотношение, нарциссизм, духовность, вера, молодые люди.

показателем здоровья личности (под «кунсткамерой» мы понимаем те отдельные случаи, когда неудовлетворенность собой толкала отдельных гениев на шедевры творчества). При этом нарциссизм, называемый фактическим «бичом» современного общества, чему как минимум способствуют призывы «глянца» и рекламы о том, что «ты самая...», и что «жизнь у нас единственная» и т.д., культивирующие исключительное отношение и любовь к себе, не имеет столь глубокого и понятного даже для большинства психологов своего понятийного и содержательного определения, как например, самоотношение, но, тем не менее, называется «подложкой» любых личностных нарушений (Х. Кохут), т.е. уже его выраженное наличие у субъекта по крайней мере косвенно определяет для психолога те или иные тенденции считать личность не достаточно зрелой.

Не менее сложным выступает вопрос отношения че- 
ловека к вере. Называемая «опиумом для народа» вера может выступать опорой и надеждой для «сирых и убогих», но вспомним Ф.М. Достоевского, считавшего, что Христос больше, чем христианство, и здесь имеется ввиду прежде всего то, на что обращает внимание Р.М. Грановская: «будь то Будда, Зороастр, Конфуций, Христос или Мухаммед (это именно личности, дополнение наше). Жизнь таких людей не только вызов существующей цивилизации, но и вдохновенное творчество. Это были гиганты чувства, добра, мысли и света» [2, с.14].

Вера покоится на эмоциональности и чувственности, в то время как наше научное мировоззрение глубоко материалистично-рационально. Однако сейчас уже мало кого из достаточно образованных людей привлекают доводы об отсутствии материального субстрата души: нет материального субстрата и сознания, являющегося многомерным явлением. Таким образом те или иные мозговые субстраты когнитивных функций, речи найдены, а сознания - нет. Даже если отсечь от веры проявления религиозности - «долю» так необходимой человечеству в каждой религии нравственных ограничений, участвующих в формировании идентичности проявлениях культа, расщепления человека на реальное и воображаемое с его желанием посмертного бытия, уже наличие таких «образцов» вершины личностного самостановления как Христос или Будда над вещностью конформизма материального обладания нивелирует у человека большинство страхов - перед бедностью, болезнью, смертью.

Экспансивная экстравертированность внешних завоеваний и собственных достижений, свойственная западной модели мировосприятия, уже сейчас привела к тому, что тотальное удовлетворение собственных потребностей современным человеком стало ощущаться им уже как неудовлетворенность собственными потребностями. Природа не знает ни Жалости, ни Справедливости, ни Совести, но они есть в Природе Человека, и их элиминирование ведет к уничтожению именно человеческой природы. И здесь даже глубоко атеистичные философы (например Ж.-П. Сартр) подчеркивают необходимость веры для человека, и здесь также подчеркивается значимость веры в содержательной структуре зрелости личности (И.Б. Дерманова, В.Р. Манукян [3]; Л.Л. Скворцова [9] и др.).

Однако вопрос отношения к вере в структуре личностной зрелости неоднозначен, как многомерен он в целом в аспектах «применимости» веры к жизни человека вообще: следование притчам, мифам и вообще всем канонам той или иной веры для современного человека многими сторонними наблюдателями оценивается часто, мягко говоря, как проявление наивна (в притчи часто превращались сюжеты, выходящие за ранг обыденного понимания и объяснения уже при создании евангелий), а жесткое и стереотипное следование меня- ющимся в связи с жизнью канонам вряд ли выглядит как условие глубокой веры, скорее как проявление ее недостатка, но следование сути веры как нравственности человечности и интерес к религии (хотя к той, которой следует большинство населения, к которому ты принадлежишь), это варианты поиска идентичности.

Любые человеческие мотивы полимодальны, и мысли о боге нередко могут подменяться мыслями о смерти, т.е., по сути, мыслями о страхе перед ней, но еще раз: любая вера прежде всего эмоциональна, как в своей основе эмоциональны ответственность и нравственность, любовь и забота. И здесь, безусловно, отношение человека к вере, особенно в контексте зрелости личности, вскрывает свои собственные нюансы.

\section{Методология (материалы и метод исследования)}

В этой связи и предпринято наше исследование, состоящее в анализе показателей самоотношения, нарциссизма и отношения к вере у лиц молодого возраста 18-33 лет (раннего - 18-21 лет, когда осуществляется обучение по избранной специальности и «пробы» в профессии, и, иногда, создание семьи, «срединного периода» ранней молодости - 22-27 лет - с «вступлением в жизнь», и «позднего периода молодости с переходом в зрелость» 28-33 лет с «закреплением в жизни»). Каждая обследованная выборка состоит из 16 человек (общее число обследованных - 48 человек), однако выборки различаются по соотношению мужчин и женщин: в группе лиц 18-21 лет число юношей и девушек равно (по 8 человек); в группе лиц 22-27 лет 5 мужчин и 11 женщин; в группе лиц 28-33 лет 2 мужчины и 14 женщин (чем старше выборка, тем менее мужчины проявляют интерес к обследованию).

Обследование было организовано методом создания специального аккаунта в Инстаграме с обращением откликнуться всех желающих соответствующего возраста и заполнить блок методик. Выборки были организованы случайным образом, с привлечением представителей различных слоев населения, с различным семейным, образовательным, профессиональным и экономическим статусом, что при таких небольших объемах выборок учесть, разумеется, было невозможно. Таким образом, при анализе были учтены лишь интересующие нас психологические показатели проявления личностной зрелости - незрелости.

Для изучения показателей самоотношения использована известная психологам и хорошо валидизованная «Методика исследования самоотношения» (далееУМИС) С.Р. Пантилеева. Для изучения показателей нарциссизма использована также достаточно хорошо известная методика «Опросник «Нарциссические черты личности» О.А. Шамшиковой и Н.М. Клепиковой. Заметим, что психологического инструментария для изучения нарциссизма 
как явления крайне мало, тем более мало инструментария для изучения отношения к вере, в связи с чем нами был использован тест на преобладающий тип духовности, автором которого является французско-бельгийский психолог Моника Тибергиен (Monique Tiberghien). Автор выделяет 4 типа духовности: 1) духовность как инструмент личностного роста и развития; 2) духовность как следование нравственному принципу (кантовскому категорическому императиву); 3) духовность как поиск и обретение мистического опыта; 4) духовность как обретение безопасного убежища (мира и покоя в душе, утоления всех печалей).

Изначально показатели перечисленных методик заданы метрическими шкалами, что не ограничивает нас в использовании статистических процедур, и в этой связи для сравнения выборок нами использовался непараметрический U-критерий Манна-Уитни, а для анализа выраженности признаков - описательные статистики. Для проведения необходимых статистических расчетов использована программа SPSS 22.0.

\section{Результаты исследования}

\section{Эмпирические гипотезы исследования:}

1. молодые люди - мужчины и женщины разных возрастных групп периода молодости могут иметь различия в показателях самоотношения, нарциссизма и выделяемых типах духовности;

2. на основании факторизации данных могут быть выделены типичные личностные «профили» составляющих личностной зрелости в молодом возрасте, учитывающие отношение к вере, а также показатели нарциссизма и самоотношения.

\section{Эмпирические задачи исследования:}

1. провести анализ различий и анализ выраженности показателей самоотношения и нарциссизма, а также превалирующих типов духовности в группах молодых людей, выделенных в рамках возрастных подгрупп периода молодости и по гендерному признаку. Осуществить частотный анализ и анализ случайности-неслучайности статической связанности выраженности показателей методики на преобладающие типы духовности с выделенными выборками;

2. провести факторизацию данных использованных методик на общей выборке.

Согласно 1-й задачи исследования осуществим оценку значимости различий для показателей методики исследования самоотношения в выделенных группах по гендерному и возрастному признакам, а также по совокупному признаку «пол - возраст» (см. Таблицу 1).

Прежде чем приступить к анализу данных, представ- ленных в Таблице 1, установим соответствие с правилом чтения U-критерия Манна-Уитни: он применим для сравнения 2-х независимых выборок, показатели которых представлены метрической шкалой, численность которых имеет ограничения $\mathrm{n}_{1}, \mathrm{n}_{2} \geq 3$ или $\mathrm{n}_{1}=2, \mathrm{n}_{2} \geq 5$, где $\mathrm{n}_{1}, \mathrm{n}_{2}$ - численность сравниваемых выборок [8, с.49], а удобство U-критерия заключается в том, что посредством него возможно осуществлять сравнение малые по численности выборки (т.е. формально мы его можем применять в нашем случае, т.к. численность мужской выборки возраста 28 лет и старше всего 2 человека), и при этом «чем меньше U, тем более достоверны различия» [8, с.49], но должно соблюдаться правило для уровня статистической значимости $\mathrm{p} \leq 0,05$, что достоверно для 95\% выборки (для $\mathrm{p} \leq 0,10$ можно вести речь о тенденциях) [7].

Однако следует иметь ввиду относительность фразы «чем меньше U, тем более достоверны различия», т.к. абсолютная величина $U$ достаточно «относительна» и зависит как от шкалы измерения (чем выше в ней показатели, тем больше может ожидаться величина U), а также от численности сравниваемых выборок вообще и разности такой численности, что мы и наблюдаем при включении в сравнение слишком малых (мужская выборка в 2 человека) и значимо превосходящих их по численности (см. Таблицу 1).

Итак, учитывая сказанное и анализируя значения, представленные в Таблице 1, нет смысла говорить о сколь-либо значимых различиях в показателях методики исследования самоотношения ни в оной из пар сравниваемых нами выборок, выделенных как по возрасту, полу, так и по полу и возрасту. При этом фактические различия для показателя «отраженное самоотношение» в сравниваемых выборках мужчин 18-21 лет и 28-33 лет $(\mathrm{U}=0,000$ при $\mathrm{p}=0,044)$ (в Таблице 1 с целью экономии места в отображении величин U все показатели после запятой 2-го и 3-го знаков исключены - это всегда нулевые значения) и в выборках мужчин 22-27 лет и 28 лет и старше (U=0,000 при $p=0,095)$ можно считать случайными и вызванными малочисленностью выборок (для возрастной группы 22-27 лет это 5 человек, для возрастной группы 28 лет и старше - всего 2 человека).

Отсутствие различий в показателях МИС С.Р. Пантилеева в сравниваемых выборках молодых людей позволяет произвести качественный анализ выраженности показателей по шкалам этой методики с опорой на описательные статистики, рассчитанные для всей выборки (см. Таблицу 2).

Диагностические нормы методики С.Р. Пантилеева очень просты: для всех «положительных шкал» (все шкалы кроме «внутренней конфликтности» и «самообвинения») диапазон средних значений от 4 до 7 баллов (минимум - 0, максимум - 10); шкала «самообвинение» 
описывается отрицательным ростом (по принципу «чем выше, тем хуже»), а для шкалы «внутренняя конфликтность» диапазон средних значений отражает положительные проявления, в то время как «амбизначения» могут говорить об отрицательных признаках, высокие о явной внутренней конфликтности, низкие об ее отрицании.

Исходя из анализа внутригрупповых средних по шкалам «открытость», «самоуверенность», «зеркальное Я», «самопринятие» и «самообвинение» обнаруживаются «уверенные» диагностические средние для данной методики. Причем «выбросы» по 1 трем названным шкалам несильно высоки, центральные и локальные моды соответствуют диапазону средних, и близость распределения внутривыборочных показателей вокруг внутривыборочных средних также подчеркивается значениями эксцессов и асимметричности по этим шкалам, хотя эксцессы по «самоуверенности», «зеркальному Я» и «самопринятию» имеют отрицательные значения, а это указывает на то, что в выборке есть существенные смещения показателей от средних как влево (к более низким значением), так и вправо (к высоким). Однако, опять же, еще раз подчеркнем, что и центральная, и локальные моды здесь находятся в диапазоне диагностических средних и эти показатели (локальных мод) имеют высокий процент представленности в выборке.

Иначе говоря, в обследованной выборке молодых людей по показателям «открытости», «самоуверенности», «зеркальному Я» и «самопринятию» методики исследования самоотношения, практическое большинство с «уверенными» средними, либо даже с высокими значениями. Для показателя «внутренняя конфликтность»

Таблица 1.

Выраженность различий и показатели уровня статистической значимости для рассчитанных значений U-критерия Манна-Уитни попарно сравниваемых групп, выделенных по гендерному, возрастному и гендерно-возрастному признакам для показателей методики исследования самоотношения (МИС)

\begin{tabular}{|c|c|c|c|c|c|c|c|c|c|c|}
\hline \multirow[b]{2}{*}{ Сравниваемые выборки } & \multirow[b]{2}{*}{ 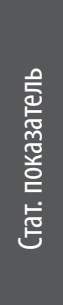 } & \multicolumn{9}{|c|}{ Шкалы методики } \\
\hline & & 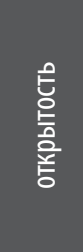 & 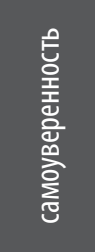 & 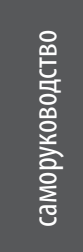 & 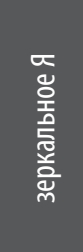 & 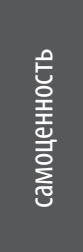 & 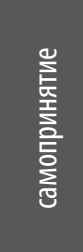 & 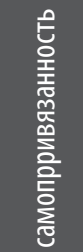 & 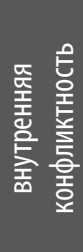 & 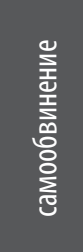 \\
\hline \multirow{2}{*}{ молодые люди возраста 18-21 и 22-27 лет } & U & 107,5 & 88,0 & 115,0 & 126,0 & 125,5 & 122,0 & 121,0 & 101,5 & 120,0 \\
\hline & $p$ & 0,445 & 0,138 & 0,642 & 0,956 & 0,926 & 0,838 & 0,809 & 0,323 & 0,780 \\
\hline \multirow{2}{*}{ молодые люди возраста 18-21 и 28-33 лет } & U & 120,5 & 113,0 & 122,0 & 114,0 & 112,0 & 109,0 & 83,0 & 73,0 & 76,5 \\
\hline & $p$ & 0,780 & 0,590 & 0,838 & 0,616 & 0,564 & 0,491 & 0,094 & 0,039 & 0,051 \\
\hline \multirow{2}{*}{ молодые люди возраста 22-27 и 28-33лет } & U & 113,5 & 71,0 & 119,0 & 117,5 & 101,5 & 102,0 & 75,5 & 106,5 & 88,0 \\
\hline & $p$ & 0,590 & 0,032 & 0,752 & 0,696 & 0,323 & 0,341 & 0,047 & 0,423 & 0,138 \\
\hline \multirow{2}{*}{ мужчины и женщины 18-21 лет } & $U$ & 24,5 & 28,0 & 31,0 & 31,0 & 31,0 & 27,0 & 31,0 & 23,0 & 27,0 \\
\hline & $p$ & 0,442 & 0,721 & 0,959 & 0,959 & 0,959 & 0,645 & 0,959 & 0,382 & 0,645 \\
\hline \multirow{2}{*}{ мужчины и женщины 22-27 лет } & U & 16,0 & 21,5 & 22,0 & 21,0 & 23,5 & 17,5 & 27,0 & 27,5 & 26,5 \\
\hline & $p$ & 0,221 & 0,510 & 0,583 & 0,510 & 0,661 & 0,267 & 1,0 & 1,0 & 0,913 \\
\hline \multirow{2}{*}{ мужчины и женщины 28-33 лет } & U & 14,0 & 8,0 & 8,0 & 2,0 & 8,0 & 5,5 & 9,0 & 9,5 & 6,0 \\
\hline & $p$ & 1,0 & 0,417 & 0,417 & 0,067 & 0,417 & 0,200 & 0,500 & 0,500 & 0,267 \\
\hline \multirow{2}{*}{ мужчины 18-21 и 22-27 лет } & U & 8,0 & 15,5 & 18,5 & 15,5 & 20,0 & 14,0 & 19,0 & 18,5 & 20,0 \\
\hline & $p$ & 0,093 & 0,524 & 0,833 & 0,524 & 1,0 & 0,435 & 0,943 & 0,833 & 1,0 \\
\hline \multirow{2}{*}{ мужчины 18-21 и 28-33 лет } & $U$ & 6,5 & 5,0 & 5,0 & 0,0 & 3,5 & 7,5 & 8,0 & 3,0 & 7,0 \\
\hline & $p$ & 0,711 & 0,533 & 0,533 & 0,044 & 0,267 & 0,889 & 1,0 & 0,267 & 0,889 \\
\hline \multirow{2}{*}{ мужчины 22-27 и 28-33 лет } & $U$ & 2,5 & 2,0 & 3,0 & 0,0 & 1,5 & 2,0 & 4,5 & 3,0 & 4,0 \\
\hline & $p$ & 0,381 & 0,381 & 0,571 & 0,095 & 0,190 & 0,381 & 0,857 & 0,571 & 0,857 \\
\hline \multirow{2}{*}{ женщины 18-21 и 22-27 лет } & $U$ & 39,5 & 30,0 & 37,0 & 39,0 & 43,5 & 33,0 & 40,5 & 30,0 & 39,0 \\
\hline & $p$ & 0,717 & 0,272 & 0,600 & 0,717 & 0,968 & 0,395 & 0,778 & 0,272 & 0,717 \\
\hline \multirow{2}{*}{ женщины 18-21 и 28-33 лет } & $U$ & 52,5 & 48,0 & 55,0 & 55,5 & 53,0 & 51,5 & 31,5 & 27,5 & 28,5 \\
\hline & $p$ & 0,815 & 0,616 & 0,973 & 0,973 & 0,868 & 0,764 & 0,095 & 0,050 & 0,059 \\
\hline \multirow{2}{*}{ женщины 22-27 и 28-33 лет } & $U$ & 73,5 & 41,0 & 62,0 & 69,5 & 65,5 & 48,0 & 42,5 & 66,5 & 47,0 \\
\hline & $p$ & 0,851 & 0,051 & 0,434 & 0,687 & 0,536 & 0,120 & 0,058 & 0,572 & 0,107 \\
\hline
\end{tabular}


Таблица 2.

Описательные статистики для показателей методики исследования самоотношения молодых людей общей выборки (мужчины и женщины 18-33 лет)

\begin{tabular}{|c|c|c|c|c|c|c|c|c|c|}
\hline \multirow[b]{2}{*}{ Статистический показатель } & \multicolumn{9}{|c|}{ Шкалы методики } \\
\hline & 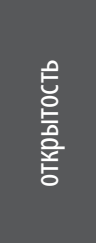 & 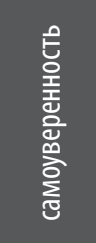 & 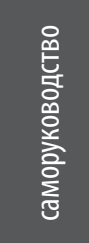 & 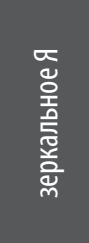 & 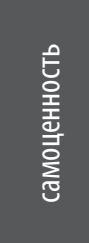 & 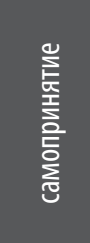 & 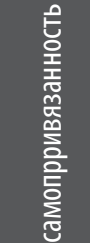 & 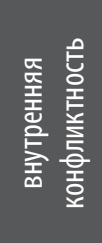 & 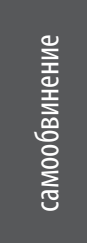 \\
\hline внутривыборочное среднее & 5,500 & 5,979 & 3,542 & 5,313 & 7,375 & 6,792 & 3,833 & 4,563 & 4,686 \\
\hline стандартное отклонение (выбросы) & 0,923 & 1,101 & 1,010 & 1,587 & 1,684 & 1,398 & 1,464 & 1,351 & 1,915 \\
\hline мода центральная & $6_{(41,7)}$ & $7_{(47,9)}$ & $4_{(45,8)}$ & $6_{(33,3)}$ & $8_{(27,1)}$ & $7_{(25,0)}$ & $5_{(27,1)}$ & $3_{(29,2)}$ & $4_{(25,0)}$ \\
\hline мода(ы) локальная (ые) & $5_{(37,5)}$ & $5_{(35,4)}$ & $3_{(25,0)}$ & $4_{(25,0)}$ & $7_{(25,0)}$ & $\begin{array}{l}8_{(22,9)} \\
5_{(20,8)} \\
6_{(18,8)}\end{array}$ & $\begin{array}{l}4_{(25,0)} \\
2_{(20,8)}\end{array}$ & $\begin{array}{l}4_{(22,9)} \\
5_{(20,8)} \\
6_{(16,7)}\end{array}$ & $\begin{array}{l}5_{(18,8)} \\
6_{(118,8)}\end{array}$ \\
\hline дисперсия выборки & 0,851 & 1,212 & 1,020 & 2,514 & 2,835 & 1,956 & 2,142 & 1,826 & 3,666 \\
\hline эксцесс & 0,837 &,- 0733 & 0,111 & $-0,474$ & $-0,286$ & $-0,724$ & $-0,790$ & $-1,058$ & 0,515 \\
\hline асимметричность & 0,509 & $-0,556$ & $-0,248$ & $-0,275$ & $-0,207$ & 0,096 & $-0,124$ & 0,375 & 0,240 \\
\hline всего лиц с низкими значениями & 0 & $2,1 \%$ & $41,7 \%$ & $10,4 \%$ & 0 & 0 & $37,5 \%$ & $29,2 \%$ & $22,9 \%$ \\
\hline всего лиц со средними значениями & $95,8 \%$ & $97,9 \%$ & $58,3 \%$ & $81,3 \%$ & $50,0 \%$ & $66,7 \%$ & $62,5 \%$ & $70,8 \%$ & $72,9 \%$ \\
\hline всего лиц с высокими значениями & $4,2 \%$ & 0 & 0 & $8,3 \%$ & $50,0 \%$ & $33,3 \%$ & 0 & 0 & $4,2 \%$ \\
\hline
\end{tabular}

Примечание: в графах со значением моды (центральная - наиболее часто встречающееся значение показателя, локальные - также часто, но реже, чем центральная мода, встречающиеся показатели) в нижнем регистре указан процент выборки с таким показателем описываемого признака

внутригрупповые средние отвечают близости к границе средних и пониженных значений, а центральная мода (29,2\% выборки) - фактически низким значениям, но локальные моды 4-6 баллов выявляются у 60,4\% выборки, и сюда можно добавить еще 10,4\% выборки (по данным частотного анализа), имеющих выраженность этого показателя в 7 баллов (диагностическое среднее), т.е. в итоге число лиц со средними значения по «внутренней конфликтности» составляет 70,8\% (с высокими нет, а с низкими, соответственно, 29,2\%, т.е. потенциально - это молодые люди, подавляющие или вытесняющие свои проблемы, что, однако, требует отдельного индивидуального подхода: может статься, что реальных проблем у них на данный момент и нет).

Показатель «самообвинение» по своим внутригрупповым средним также находится в диапазоне диагностических средних; здесь же находятся центральная и локальные моды (4-6 баллов: общая представленность в выборке $62,6 \%+10,4 \%$ лиц с «нормативной» с точки зрения диагностических средних для методики выраженностью показателя в 7 баллов; итого 73\% выборки со средней выраженностью самообвинения; при этом по данным частотного анализа 22,9\% выборки имеют низкое самообвинение и всего 4,2\% высокое, что вполне хорошо для выборки).

Итак, в обследованной выборке молодых людей по шкалам методики исследования самоотношения: «открытость», «самоуверенность», «зеркальное Я», «самопринятие», «внутренняя конфликтность» и «самообвинение» выявляются вполне позитивные итоги, в основном «центрируемые» вокруг невыраженности признаков, т.е. средних значениях.

Показатель «самоценность» и в величинах внутригруппового среднего, и в значениях модальных величин соотносим с диагностическими средними методики (в сумме у 50\% выборки по данным частотного анализа, но остальные 50\% выборки имеют высокие значения.

Несколько хуже обстоит дело в обследованной выборке молодых людей с показателями «саморуководство» (58,3\% выборки имеют средние значения и 41,7\% низкие, высоких нет) и «самопривязанность» (у 62,5\% средние значения и у 37,5\% низкие, высоких показателей нет). В интерпретационных характеристиках методик это означает, что 42\% молодых людей имеют пониженную 
саморегуляцию, недостаточную «сфокусированность Я», подвластны влияниям обстоятельств (низкий локус контроля) и 38\% испытывают значимую неудовлетворенность собой.

Перейдем к рассмотрению показателей нарциссизма, для чего также сравним выборки, выделенные по признакам пола, возраста, и признаку «пол - возраст» (см. Таблицу 3).

Согласно анализу данных, представленных в Таблице 3 в сравниваемых выборках молодых людей есть кране слабые различия в «отсутствии эмпатии» в выборках возрастов 18-21 лет и 22-27 лет, но проявляющие себя на уровне тенденций, а также в «сверзанятости чувством зависти» в выборках возрастов 18-21 лет и 28-33 лет: различия явные, но очень слабые. Есть определенные различия у мужчин и женщин 18-21 лет в показателе «ожидание особого отношения», причем у юношей этот показатель несколько выше $(M=26,5$ при $\sigma=2,7)$ чем у девушек ( $M=22,8$ при $\sigma=3,5)$, но показатели очень близки и в обоих случаях относятся к диагностическим средним, а также в показателе «отсутствие эмпатии», он у юношей также выше ( $M=30,0$ при $\sigma=3,3)$ и относится к повышенным значением, в то время как у девушек $(M=26,4$ при $\sigma=3,9)$ к средним.

Есть определенные различия у мужчин и женщин 2227 лет в показателе «дерзкое, заносчивое поведение», который у мужчин ( $M=18,0$ при $\sigma=4,0)$ несколько выше, чем у женщин ( $M=14,9$ при $\sigma=2,6)$, однако оба этих значения находятся в интервале диагностических низких.

Таблица 3.

Выраженность различий и показатели уровня статистической значимости для рассчитанных значений

U-критерия Манна-Уитни попарно сравниваемых групп, выделенных по гендерному, возрастному и гендерно-возрастному признакам для показателей методики «Нарциссические черты личности» (НЧЛ)

\begin{tabular}{|c|c|c|c|c|c|c|c|c|c|c|}
\hline \multirow[b]{2}{*}{ Сравниваемые выборки } & \multirow[b]{2}{*}{ 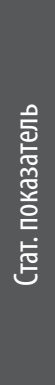 } & \multicolumn{9}{|c|}{ Шкалы методики } \\
\hline & & 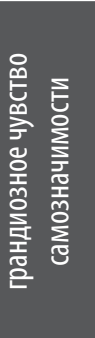 & 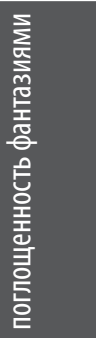 & 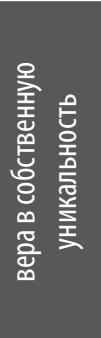 & 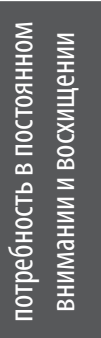 & 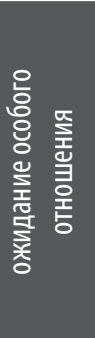 & 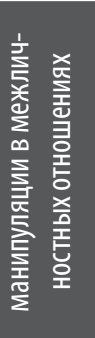 & 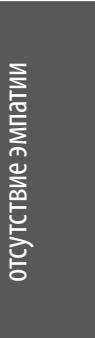 & 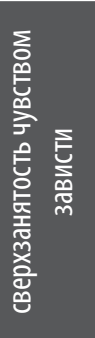 & 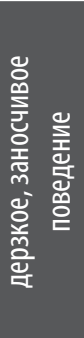 \\
\hline \multirow{2}{*}{ молодые люди возраста 18-21 и 22-27 лет } & U & 121,0 & 120,0 & 120,0 & 109,5 & 121,0 & 126,0 & 85,5 & 113,0 & 113,5 \\
\hline & $p$ & 0,809 & 0,780 & 0,780 & 0,491 & 0,809 & 0,956 & 0,110 & 0,590 & 0,590 \\
\hline \multirow{2}{*}{ молодые люди возраста 18-21 и 28-33 лет } & $U$ & 108,5 & 115,0 & 126,5 & 100,5 & 120,5 & 97,0 & 103,0 & 76,5 & 117,0 \\
\hline & $\mathrm{p}$ & 0,468 & 0,642 & 0,956 & 0,305 & 0,780 & 0,254 & 0,361 & 0,051 & 0,696 \\
\hline \multirow{2}{*}{ молодые люди возраста 22-27 и 28-33лет } & $U$ & 127,0 & 111,5 & 125,5 & 87,5 & 122,5 & 104,0 & 102,0 & 80,5 & 126,5 \\
\hline & $p$ & 0,985 & 0,539 & 0,926 & 0,128 & 0,838 & 0,381 & 0,341 & 0,073 & 0,956 \\
\hline \multirow{2}{*}{ мужчины и женщины 18-21 лет } & $U$ & 23,5 & 24,0 & 25,0 & 19,5 & 12,0 & 21,5 & 15,0 & 31,0 & 20,0 \\
\hline & $p$ & 0,382 & 0,442 & 0,505 & 0,195 & 0,038 & 0,279 & 0,083 & 0,959 & 0,234 \\
\hline \multirow{2}{*}{ мужчины и женщины 22-27 лет } & U & 21,0 & 27,0 & 18,5 & 27,0 & 20,5 & 21,0 & 25,0 & 25,0 & 10,5 \\
\hline & $\mathrm{p}$ & 0,510 & 1,0 & 0,320 & 1,0 & 0,441 & 0,827 & 0,827 & 0,827 & 0,052 \\
\hline \multirow{2}{*}{ мужчины 18-21 и 22-27 лет } & U & 15,0 & 16,0 & 16,5 & 19,5 & 11,5 & 13,5 & 7,5 & 19,5 & 19,0 \\
\hline & $p$ & 0,524 & 0,622 & 0,622 & 0,943 & 0,222 & 0,354 & 0,065 & 0,943 & 0,943 \\
\hline \multirow{2}{*}{ женщины 18-21 и 22-27 лет } & $U$ & 40,0 & 37,5 & 40,0 & 30,5 & 25,0 & 34,0 & 37,0 & 36,0 & 42,5 \\
\hline & $p$ & 0,778 & 0,600 & 0,778 & 0,272 & 0,129 & 0,442 & 0,600 & 0,545 & 0,904 \\
\hline \multirow{2}{*}{ женщины 18-21 и 28-33 лет } & $U$ & 49,0 & 37,5 & 53,5 & 55,0 & 36,5 & 50,0 & 52,5 & 31,5 & 54,0 \\
\hline & $p$ & 0,664 & 0,212 & 0,868 & 0,973 & 0,188 & 0,714 & 0,815 & 0,095 & 0,920 \\
\hline \multirow{2}{*}{ женщины 22-27 и 28-33 лет } & U & 76,0 & 56,5 & 74,0 & 54,0 & 64,0 & 58,5 & 62,5 & 45,0 & 76,5 \\
\hline & $p$ & 0,979 & 0,267 & 0,893 & 0,222 & 0,501 & 0,317 & 0,434 & 0,085 & 0,979 \\
\hline
\end{tabular}

Примечание: учитывая предыдущий анализ, не представлены данные сравнения с участием малой по численности выборки мужчин возрастной группы 28 лет и старше (2 человека) 
Также есть различия в сравниваемых выборках мужчин возрастных групп 18-21 лет и 22-27 лет по показателю «отсутствие эмпатии», и этот показатель несколько менее $(M=26,0$ при $\sigma=5,7)$ выражен у мужчин более возрастной группы 22-27 лет, чем у более молодой $(M=30,0$ при $\sigma=3,3$ ) (соответственно: диагностические средние и повышенные значения).

В целом же мы видим, что явных и существенных различий по всем показателям методики «Нарциссические черты личности» в сравниваемых группах молодых людей, выделенных по признакам пола, возраста и «пол возраст» нет. В этой связи мы имеем полное право проводить анализ выраженности показателей указанной методики на массиве данных общей выборки.

Для большей ясности картины нами были переведены показатели каждого респондента по указанной методике в относительную выраженность низких, средних и высоких значений: это тем более удобно в том случае, что каждая шкала методики имеет для них собственные диагностические диапазоны.

Представим в Таблице 4 процентное соотношение лиц общей выборки с высокими, средними и низкими частными показателями нарциссизма.

Как видно из Таблицы 4, существенная часть респондентов (а иногда, и преимущественная) имеет низкие частные показатели нарциссизма, и лишь фактически только по «отсутствию эмпатии» есть существенная часть лиц с высокими показателями. Большое число лиц с низкими частными показателями нарциссизма вызывает у нас два вопроса: во-первых, хорошо это или плохо, и во-вторых, одни ли это и те же лица? Начнем со второго вопроса, ответ на который может быть легко получен статическим, а именно - методом корреляционного анализа.

Величины корреляционных связей (r-Пирсона) для связей 1-го показателя («грандиозное чувство самозначимости») следующие: с «поглощенностью фантазиями» $\mathrm{r}=0,584$ при $\mathrm{p}=0,000$; $\mathrm{c}$ «верой в собственную уникальность» $r=0,468$ при $p=0,001$; $c$ «потребностью в постоянном внимании и восхищении» $r=0,422$ при $p=0,003$; c «ожиданием особого отношения» $r=0,220$ при $p=0,133$; с «манипуляциями в отношениях» $r=0,021$ при $p=0,886$; c «отсутствием эмпатии» $r=-0,558$ при $p=0,000$; со «сверхзанятостью чувством зависти» $r=-0,186$ при $p=0,205$; с «дерзким и заносчивым поведением» $r=0,438$ при $p=0,002$.

На наш взгляд корреляции очень показательные, что мы затронем несколько позже мы порассуждаем позже. А сейчас вернемся к первому вопросу. Еще во Введении настоящего исследования мы говорили о сложности и неоднозначности феномена нарциссизма. Вернемся к этому. По сути, многими людьми гордыня и нарциссизм считаются явлениями схожими, или, по крайней мере, близкими. Напомним, что первым, кто был одержим грехом гордыни, был падший ангел Люцифер - любимец Бога, возомнивший себя равным Богу, если Его не превосходящим.

Однако напомним также, что в православии гордыней называют не только высокомерие, фактически отрицающее Бога, но в большинстве случаев считают признаками гордыни и постоянное самоуничижении. На наш взгляд гордыня отличается от нарциссизма только объектами сравнения: для гордыни - это Бог, для нарциссизма - люди. Вернемся к нарциссизму как психологическому и психиатрическому явлению. У нас в стране нарциссизм как отдельный психиатрический диагноз фактически или вообще не применяют. «Согласно DSM APA - классификатора «Диагностическое и статистическое руководство по психиатрическим заболеваниям Американской психиатрической ассоциации» диагноз «нарциссическое расстройство личности» может быть поставлен лишь при наличии не менее чем пяти устой-

Процентная представленность молодых людей общей выборки (мужчины и женщины 18-33 лет)

Таблица 4. с низкими, средними и высокими частными показателями нарциссизма, \%

\begin{tabular}{|c|c|c|c|c|c|c|c|c|c|}
\hline \multirow[b]{2}{*}{ Выраженность показателя } & \multicolumn{9}{|c|}{ Шкалы методики } \\
\hline & 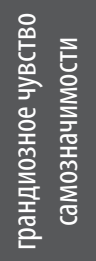 & 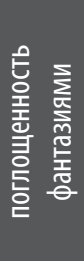 & 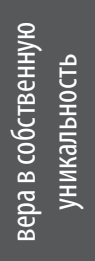 & 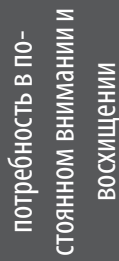 & 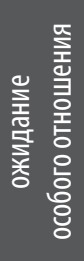 & 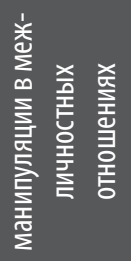 & 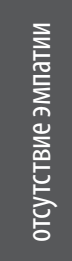 & 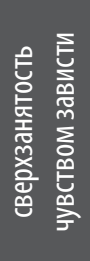 & 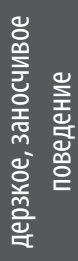 \\
\hline низкая & 72,9 & 18,8 & 97,9 & 47,9 & 4,2 & 6,3 & 0 & 58,3 & 87,5 \\
\hline средняя & 27,1 & 81,3 & 2,1 & 52,1 & 95,8 & 87,5 & 64,6 & 41,7 & 12,5 \\
\hline высокая & 0 & 0 & 0 & 0 & 0 & 6,3 & 35,4 & 0 & 0 \\
\hline
\end{tabular}


чивых черт при условии, если они наблюдаются не менее полугода. В остальных случаях речь идет о состояниях или переходных формах нарциссизма, которые возникают вследствие угрозы целостности представлений личности о себе. Выделяют 9 нарциссических черт: 1) «грандиозное чувство собственной значимости; 2) вера в собственную уникальность; 3) потребность в постоянном внимании и восхищении; 4) поглощенность фантазиями; 5) манипуляции в межличностных отношениях; 6) дерзость и заносчивость поведения; 7) ожидания особого отношения; 8) дефицитарность эмпатии; 9) сверхзанятость чувством зависти» [10, с.153].

Это фрагмент статьи О.А. Шамшиковой и Н.М. Клепиковой, выпустивших в свет в 2010 г. методику «Нарциссические черты личности», шкалы которой полностью перечисляют в DSM APA частные показатели нарциссизма. Однако необходимо иметь ввиду, что нарциссизм по мнению ряда ученых содержит в себе и обратную, или, точнее, «изнаночную» или «оборотную» сторону, которая оказывается ничуть не «лучше» «лицевой» - это те же проблемы, только маскируемые в своих проявлениях и выражениях, и, особенно, в вопросах психосоматики.

В этой связи, в частности С.М. Джонсон [4] в 3-х формах экспрессии нарциссизма выделяет проявления фальшивого Self с зависимостью от успехов, педантизмом, чувством собственной значимости, гордостью, излишней требовательностью (что часто сопровождается перфекционизмом), и сосредоточенностью на себе (привычное в той или иной мере всем понимание нарциссизма); симптоматического Self с чувствительностью к стыду и унижению, ипохондричностью и психосоматическими явлениями, переживанием ничтожности и самообесцениванием, депрессивностью, инертностью, перерывами в работе, ранимостью самолюбия и стремлением к изоляции.

Истинное же Self для обеих форм нарциссизма схоже: ощущение пустоты, никчемности, паники с ослаблением и фрагментацией Self. В целом же по Джонсону нарциссизм - это прокламация фальшивого Self, которому отдается преимущество перед Self настоящим. Казалось бы, все с пониманием нарциссизма прозрачно: критерии выделены, и они достаточно глубоко психопатологичны, но все чаще различные авторы приходят к тому, что современный человеческий мир все более и более погружается в пучину нарциссизма: мы все более любим себя и все меньше склонны обращать внимание на других, и это уже проявляет себя в отказе от создания семьи и деторождения вообще, и целом ряде других явлений.

На наш взгляд проблема нарциссизма в некоторых местах сближается с проблемой самооценивания, что проявляет себя в частности в инфляции «Я» при «явном» нарциссизме и неадекватно завышенной самооценке, и дефляции «Я» при симптоматическом нарциссизме (иногда в своей выраженной форме его называют эхотическим нарциссизмом (по примеру нимфы Эхо, влюбленной в Нарцисса и не получившей ответа) и заниженной самооценке.

Однако на наш взгляд проблемы с самооценкой носят прежде всего психологический характер, в то время как нарциссизм - это прежде всего болезнь души (часто проблема нравственности человека). Б.С. Братусь [1] выделяет в самооценке ценностную («я оцениваю себя как самоценность») и операционно-техническую («что я умею делать и делаю, и как я это делаю») компоненты. При этом он обращает внимание на то, что у невротиков часто операционно-техническая самооценка занижена, что они чаще всего компенсируют ценностной самооценкой, правда, нередко, для ее объективизации что-то предпринимая, например, «уходя» в культуру, саморазвитие и т.д.

Отчасти, это решение симптоматического нарциссизма. Хорошо, на наш взгляд, проявление нарциссизма отражает анекдот-сентенция (отдельный вопрос, как, когда и кем сочинялись подобные анекдоты), включающий в себя всего три фразы: «армяне лучше, чем грузины! Чем лучше? Чем грузины!». В применимости к личности можно привести и такие косвенные реакции: «если мне платят больше, значит я этого заслуживаю», «я живу лучше, чем ты, значит я лучше, чем ты» и т.д. Таким образом, в фокусе нарциссического сравнения фактически полностью отсутствует анализ объективного и содержательного.

На наш взгляд, выделяемые DSM APA девять признаков нарциссизма - это удобная национальная и политическая уловка, благодаря которой можно не обращать внимание на высокомерие отдельных чиновников, различное отношение к воровству («если ты украл у соседа мешок яблок - ты вор, но если ты украл вагон спирта, то ты - будущий олигарх» - одно из любимых изречений нашего народа в «лихие 90-е», и т.д.; известно, что эпилептоидная акцентуация признана только у нас в стране и во Франции. Как её признавать в Америке с её культом ковбойского «мачо», или, например, в Канаде, где «крутые» лесорубы - национальная гордость?).

В этой связи проблема нарциссизма гораздо глубже и многограннее. И в этой же связи со всей очевидностью методика «Нарциссические черты личности» О.А. Шамшиковой и Н.М. Клепиковой вообще не принимает во внимание любые представления о симптоматическом нарциссизме и низкие показатели по ней говорят лишь об отсутствии явных проявлений фальшивого Self. Но, при этом, сложность проблемы нарциссизма подчеркивается и выявленными нами корреляционными связями, как минимум, одного показателя «грандиозное чув- 
ство самозначимости» (а он здесь чуть-ли не ведущий) с другими: связи хотя и не тесные, но прямые со всеми показателями, кроме «отсутствия эмпатии» и «сверхзанятостью чувством зависти» (здесь они обратные). То, что связи не тесные и в ряде случаев значения уровня статистической значимости не достигают необходимого уровня - это, по сути, статистические «мелочи», которые могут поменять свои величины с увеличим выборки.

Однако напомним, что прямые связи означают, что рост одного признака ведет к росту другого признака, т.е. проявление «грандиозного чувства самозначимости» ведет и к проявлению других (а у нас это также означает, что лица с малой выраженностью этого признака имеют и малую выраженность других частных показателей нарциссизма), а обратные корреляционные связи означают, что рост одного признака ведет к уменьшению тех, которые с ним корреляционно связаны обратно. У нас с «грандиозным чувством самозначимости» обратно связаны «отсутствие эмпатии» и «сверхзанятость чувством зависти».

Мы проверили методику «Нарциссические черты личности» О.А. Шамшиковой и Н.М. Клепиковой с включением всех её шкал на внутреннюю согласованность (надежность) по а-Кронбаха и величина коэффициента составила на нашей выборке 0,402 - показатель «не ахти какой», или, прямо, скажем, этот показатель соответствует недостаточной $(\leq 0,5)$ надежности, но, все же, методика отражает в себе суть завяленных ею выявляемых явлений. Однако выявленные нами обратные связи «грандиозного чувства самозначимости» с «отсутствием эмпатии» и «сверхзанятостью чувством зависти» говорят лишь о том, что современные «Нарциссы» и обладают достаточным эмоциональным интеллектом (в структуру которого эмпатия входит), и не так проявляют себя в зависти к другим уже потому, что более стремятся не завидовать, а использовать других («постулаты» нарциссической личности получили свою наибольшую разработанность в 60-80-е гг. прошлого столетия, но, со всей очевидностью, человек меняется).

Итак, подведем итоги: большая часть обследованных нами молодых людей имеет низкие и средние показатели нарциссизма, но исключение составляет показатель «отсутствие эмпатии», обнаруживающий свою высокую выраженность у фактической 1/3 выборки, и, при этом, остальные часть выборки представлены лицами со средней выраженностью этого показателя (средний уровень эмпатии), что уже создает предпосылки понимать ситуацию (треть выборки с «отсутствием эмпатии») как угрожающую с точки зрения наличия предикторов нарциссизма; показатели нарциссизма в основном прямо, хотя и не сильно связаны между собой, за исключением связей с «отсутствием эмпатии» и «сверзанятостью чувством зависти», что позволяет судить об изменении про- явлений нарциссизма у современных людей; методика «Нарциссические черты личности» О.А. Шамшиковой и Н.М. Клепиковой полностью построена на классификаторе «Диагностическое и статистическое руководство по психиатрическим заболеваниям Американской психиатрической ассоциации» и не учитывает «изнаночные» проявления нарциссизма, что не позволяет однозначно говорить о его отсутствии у лиц, чьи показатели по этому тесту минимальны, и, в целом, прогностичность методики слаба (альфа Кронбаха 0,402 $\leq 0,5$, что говорит о ее недостаточной надежности).

Перейдем к рассмотрению вопроса отношения к вере. Напомним, что тест на духовность содержит в себе 4 шкалы, отражающие в баллах понимание субъектом духовности в 4 аспектах: 1) духовность как инструмент личностного роста и развития; 2) духовность как следование нравственному принципу (кантовскому категорическому императиву); 3) духовность как поиск и обретение мистического опыта; 4) духовность как обретение безопасного убежища (мира и покоя в душе, утоления всех печалей).

Сразу заметим, что нами был просчитан коэффициент альфа Кронбаха, составивший значение 0,421 - с очевидностью низкое, но, по крайней мере, методика действительно «работает» «на духовность». Для удобства анализа нами были выделены доминирующие, субдоминантные и отвергаемые типы духовности, что, безусловно, является условным уже в силу того, что при возможном максимуме баллов в 12 единиц отдельными респондентами были получены максимальные оценки, равные 6 баллам.

Мы присвоили соответствующие статистические метки для доминирующих, субдоминантных и отвергаемых типов духовности, используя для себя правило: максимальная выраженность признака, если она находится в диапазоне от 10 до 12 баллов, относилась к доминирующему типу духовности, и здесь также выбирался единственный тот тип духовности, выраженность по которому была больше; соответственно, к субдоминантному типу относился тот тип (или их сочетание), выраженность по которым также относилась к выраженности своего показателя 8-10 баллов, но из них также выделялся наибольший (например, в 9 баллов при наличии 2 других в 8 баллов), но признаки в 9-8 баллов относились уже к субдоминантным без наличия здесь доминирующего признака; типы духовности с выраженностью признака в 7 баллов и ниже, если иных не выявлялось, относились к неопределенным (нулевая метка) и не учитывались в качестве доминирующих и субдоминантных, но учитывались отвергаемые типы духовности, показатели которых были 3 и ниже баллов.

Далее были определены значения Хи-квадрат Пирсо- 
на для выявления случайности-неслучайности частного распределения в связи с полом и возрастом респондентов (см. Таблицу 5).

Согласно данным, представленным в Таблице 5, статистической связанности частотного распределения типов духовности в отношении доминирующего, субдоминантного и отвергаемого предпочтений ни в связи с полом (даже если учитывать, что уровень статистической значимости для Хи-квадрат Пирсона двухсторонний, и его величины могут быть поделены надвое в случаях для связи субдоминантного и отвергаемого типов духовности в связи с полом, и благодаря этому можно было бы вести о тенденциях связи, что не имеет смысла), ни с возрастом нет.

Проведем частотный (сразу процентный) анализ для общей выборки. Для доминирующего типа духовности преобладание каких-либо выборов отсутствует у 52,1\% респондентов; у 20,8\% это духовность как инструмент личностного роста и развития; у 14,6\% это духовность как следование нравственному принципу; остальные выборы, в том числе и сочетанные, представлены крайне слабо $(2,1 \%$ и $4,2 \%)$.

Для субдоминантного типов духовности преобладание выборов отсутствует у 43,8\% выборки; у 16,7\% это духовность как инструмент личностного роста и развития; у 14,6\% выборки это духовность как следование нравственному принципу; остальные выборы представлены слабо (6,3-2,1\%\%).

Для отвергаемых типов духовности выборы отсутствуют у 60,4\% респондентов; для 16,7\% выборки это духовность как поиск и обретение мистического опыта; для 14,6\% респондентов это духовность как обретение безопасного убежища; остальные выборы представлены слабо (2,1\% и 4,2\%).

На основании полученных данных можно говорить о том, что большинство обследованных нами молодых людей не имеет четко сформированного отношения к вере: только примерно для каждого пятого из них духовность - это «место приложения» их культурно-исторических аспектов саморазвития и еще примерно для 17\% из них это уже имеет не такой важный по значимости интерес, и лишь примерно для 15\% респондентов вера сопряжена с нравственностью, и еще примерно для 15\% отношение к подобной нравственности может быть сформулировано по принципу «ну, может быть, в определенных условиях».

Подводя итоги по 1 задаче исследования, мы не можем говорить о сколь-либо существенных различиях, да, и в целом, скорее следует вести речь об отсутствии таковых, для показателей самоотношения, нарциссизма и отношения к вере у молодых мужчин и женщин, а также об их условной динамике в связи с возрастом (точно можно говорить о таковой лишь в случае лонгитюдного исследования). Значимых признаков нарциссизма нами не выявлено, что, однако, с нашей точки зрения не указывает на их отсутствие, но на определенные недочеты методики.

Показатели самоотношения в целом средние. Отношение к вере - не на «высоте». Как все это соотносится с личностной зрелостью - обсудим ниже. В целом же полученные результаты идут вразрез с 1 гипотезой: молодые люди - мужчины и женщины разных возрастных групп периода молодости могут иметь различия в показателях самоотношения, нарциссизма и выделяемых типах духовности.

Для определения связи между показателями использованных в работе методик мы использовали процедуру факторизации данных (без вращения референтных осей), но с определением критерия КМО и сферичности Бартлетта, составившем величину 0,518, что позволяет считать факторный анализ признанным для нашей выборки (но с низкой адекватностью [6, с.294]).

«Осыпь» графика собственных значений (см. Рисунок 1) уже начинается после 1-го фактора (его вклад в обобщенную дисперсию выборки составляет 20,5\%) и очевидна («каменистая осыпь» в терминологии Р. Кеттелла) после 2-го фактора и его вклад в обобщенную дисперсию выборки 12,4\%; вклад 3-го фактора 11,9\%, остальных существенно ниже. Таким образом к рассмотрению мы допустили пока что 1 фактор. Связи в нем и «веса» с соответствующими знаками присутствия в факторе показателей методик отражены в Таблице 6.

И хотя вклад в обобщенную дисперсию выборки представленного в Таблице 6 фактора составляет всего

Таблица 5.

Значения Хи-квадрат Пирсона и уровня статистической значимости для связи распределения доминирующих, субдоминантных и отвергаемых типов духовности с полом и возрастом респондентов

\begin{tabular}{c|c|c|c|c|c|c|}
\hline \multirow{2}{*}{$\begin{array}{c}\text { Выделенная } \\
\text { выборка }\end{array}$} & \multicolumn{2}{|c|}{ Доминирующий тип духовности } & \multicolumn{1}{c|}{ Субдоминантный тип духовности } & \multicolumn{2}{|c|}{ Отвергаемый тип духовности } \\
\cline { 2 - 7 } & $\chi^{2}$ & $p$ & $\chi^{2}$ & $p$ & $\chi^{2}$ & $p$ \\
\hline по полу & 0,787 & 0,341 & 10,681 & 0,220 & 7,324 & 0,198 \\
\hline по возрасту & 10,920 & 0,536 & 14,821 & 0,538 & 8,605 & 0,570 \\
\hline
\end{tabular}




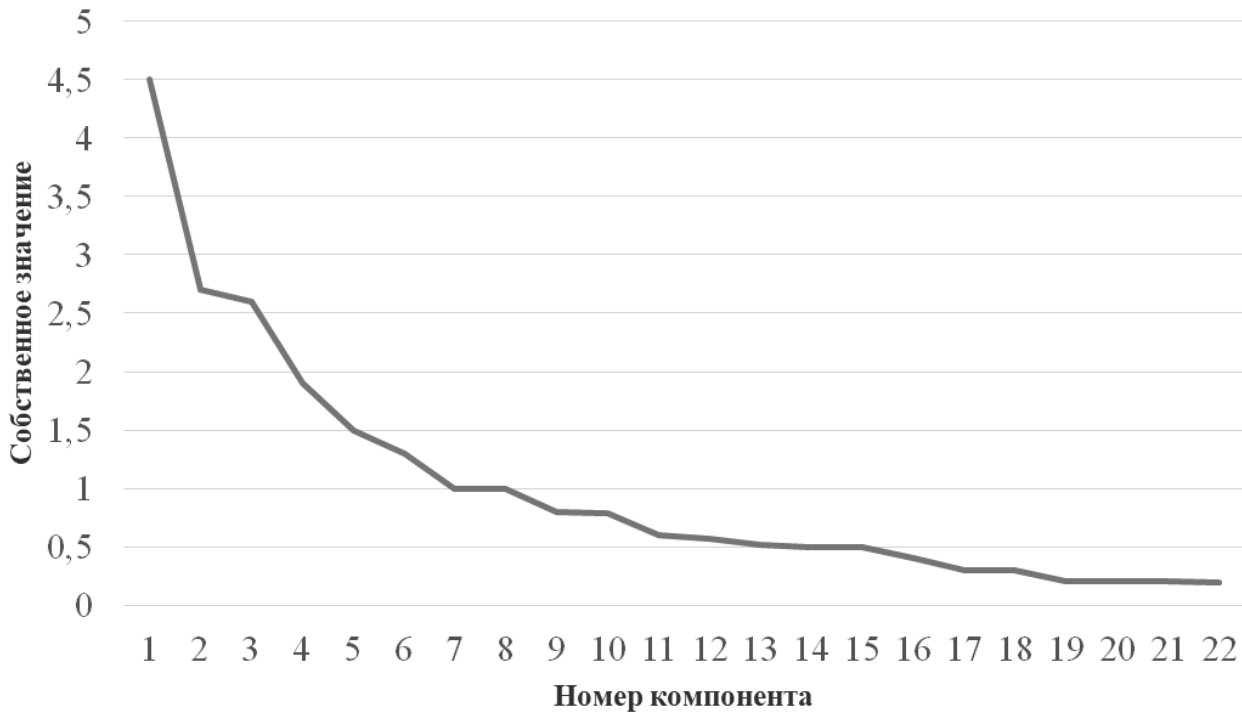

Рис. 1. График собственных значений факторов

Таблица 6.

Показатели и их весовые нагрузки в факторе №1

\begin{tabular}{|l|c|}
\multicolumn{1}{|c|}{ Показатель методики * } & $\begin{array}{c}\text { «Весовое» присутствие в факторе } \\
\text { и направленность }\end{array}$ \\
\hline открытость (МИС) & 0,261 \\
\hline самоуверенность (МИС) & 0,676 \\
\hline саморуководство (МИС) & 0,536 \\
\hline зеркальное Я (МИС) & 0,531 \\
\hline самоценность (МИС) & 0,477 \\
\hline самопринятие (МИС) & 0,394 \\
\hline самопрривязанность (МИС) & 0,350 \\
\hline внутренняя конфликтность (МИС) & $-0,644$ \\
\hline самообвинение (МИС) & $-0,640$ \\
\hline грандиозное чувство самозначимости (НЧЛ) & 0,647 \\
\hline поглощенность фантазиями (НЧЛ) & 0,451 \\
\hline вера в собственную уникальность (НЧЛ) & 0,453 \\
\hline потребность в постоянном внимании и восхищении (НЧЛ) & 0,311 \\
\hline ожидание особого отношения (НЧЛ) & $-0,075$ \\
\hline манипуляции в межличностных отношениях (НЧЛ) & $-0,259$ \\
\hline отсутствие эмпатии (НЧЛ) & $-0,642$ \\
\hline сверхзанятость чувством зависти (НЧЛ) & $-0,565$ \\
\hline дерзкое, заносчивое поведение (НЧЛ) & 0,322 \\
\hline вера как инструмент (ТД) & 0,317 \\
\hline вера как нравственный принцип (ТД) & $-0,054$ \\
\hline вера как мистика (ТД) & 0,302 \\
\hline вера как убеежище (ТД) & 0,260 \\
\hline
\end{tabular}

Примечание: *(МИС - методика исследования самоотношения»; НЧЛ - «нарииссические черты личности»; ТД - «тест на духовность» 
около 20\%, но это все же означает, что такой «психологический потрет» описывает фактически каждого 5-го из обследованных нами молодых людей, но представленные в Таблице 6 данные преподносят явные сюрпризы. В факторе с положительными весами (прежде всего, обратим внимание на средние, выше их нет, и умеренные $(0,30-0,49)$ представлены все показатели самоотношения («открытость» также с прямым, но слабым) (понятно, что «внутренняя конфликтность» и «самообвинение»- с обратными) и следующие показатели нарциссизма (с прямыми!): «грандиозное чувство самозначимости», «поглощенность фантазиями», «вера в собственную уникальность» и «потребность в постоянном внимании и восхищении», а также «дерзкое, заносчивое поведение», и, кроме того, в факторе также присутствуют с прямыми весовыми нагрузками отношения к вере в показателях «вера как инструмент» и «вера как мистика» (но также со слабой нагрузкой «вера как убежище»).

С обратными весами представлены частные показатели нарциссизма «отсутствие эмпатии» и «сверхзанятость чувством зависти» (и об этом мы уже говорили, когда обсуждали корреляционные связи внутри методики на нарциссизм), а также «манипуляция в межличностных отношениях» (хотя и со слабой нагрузкой). Почему показатели самоотношения прямо связаны с большинством показателей нарциссизма, выглядит парадоксом. Но на этом мы остановимся несколько позже.

Получив такие результаты, закономерен вопрос о связях показателя веры как нравственного принципа с другими показателями (по Канту, «поступай с другими также, как если бы ты хотел, чтобы другие поступали с тобой»). Более всего этот показатель («вера как нравственный принцип») наиболее выражен (и, к тому же представлен положительной весовой нагрузкой (средней и равной 0,560) в 3-м факторе, вклад которого в обобщенную дисперсию выборки составил 11,9\%, что, собственно, не много (т.е. фактически в выборке это описание каждого 10-го человека), но если отбросить все веса с уровнем ниже умеренных, то этот показатель обратно связан со всеми остальными показателями отношения к вере (со средними весами, но обратными нагрузками в факторе представлены отношения к вере как к инструменту $(-0,653)$, мистике $(-0,689)$ и убежищу $(-0,576))$, но, что более важно, в факторе с прямыми, но умеренными весами представлены частные показатели нарциссизма: «грандиозное чувство самозначимости» $(0,426)$, «потребность в постоянном внимании и восхищении» $(0,407)$, «ожидание особого отношения к себе» $(0,474)$ и «дерзкое, заносчивое поведение» $(0,416)$. Показатели самоотношения представлены очень слабо $(\leq 0,19)$ или слабо $(0,20-0,29)$ и наиболее сильно из них с отрицательным знаком представлена «внутренняя конфликтность» $(-0,273)$.
Таким образом, результаты факторизации в обоих случаях, казалось бы, обескураживают. При этом весовые нагрузки и «знаковое» присутствие показателя в факторе следует понимать фактически также, как и корреляционные связи (факторный анализ строится на принципах корреляционного): положительная связь показателей означает, что рост одного ведет к росту другого, отрицательная - к уменьшению. Весовая же нагрузка, как и сила корреляционной связи одновременно означает и вероятность присутствия признака, и его выраженность.

Таким образом, для 3-го фактора отношение к вере как нравственному принципу не сопоставимо с отношением к вере как убежищу, явлению мистики и возможности личностного роста, но вероятностно с проявлением вероятности от 0,4 и, почти, до 0,5 может встречаться с частными проявлениями нарциссизма требованием к себе внимания и восхищения, ростом чувства самозначимости и ожиданием к себе особого отношения. Еще более неприглядная картина наблюдается в однонаправленных сочетаниях в факторе №1 ряда показателей нарциссизма и ряда позитивных показателей самоотношения. Казалось бы: нарциссизм - это негативное личностное явление, а на высокую значимость позитивного самоотношения в структуре личностной зрелости указывают все авторы, ее изучающие. Как эти явления могут между собой сочетаться?

На наш взгляд, совершенно естественным образом. В греческом мифе Нарцисс любуется собственным отражением в воде; в психоаналитических концепциях нарциссизм - это любовь к себе (речь идет лишь о границах такой любви, что отличает «нормальный» нарциссизм от призраков злокачественного (по О. Кернбергу). Таким образом, совершенно естественно, что «психологический нарцисс» имеет к себе весьма позитивное отношение и нарциссизм может быть понят нами как комплекс специфического самозащитного поведения личности, хотя и весьма утрированного (с психологическими защитами его также сближает эго-синтонность).

Но рассмотрение нами 1-й исследовательской задачи во всем ее объеме показало, что подавляющее большинство обследованных молодых людей имеет нормативные средние показатели самоотношения и большая часть из них имеет средние и даже низкие частные показатели нарциссизма. Какими являются проявления «нормального», «здорового» нарциссизма, методика «Опросник «Нарциссические черты личности» О.А. Шамшиковой и Н.М. Клепиковой не описывает, и мы в факторном анализе оперировали терминами, в основном представленными DSM APA (т.е. теми, какие заданы методикой). Статистическая же связанность (т.е. собственно математическая) явлений отражает характер тенденций в изменении признака. Так, например, в 1-м факторе са- 
моуверенность по МИС $(0,676)$ и грандиозное чувство самозначимости теста на нарциссизм $(0,647)$ средне связаны между собой и их положительное присутствие в факторе означает, что рост самоуверенности как показателя самоотношения (буквально «представления о себе как самостоятельном, волевом, энергичном, надежном человеке, которому есть за что себя уважать») ведет к росту у себя чувства самозначимости как нарциссического проявления.

Но еще раз подчеркнем, что по данным рассмотрения 1-й задачи показатели у респондентов преимущественно средние или даже низкие, т.е. факторные связи выявляют характер взаимоотношений между названными признаками (рот одного ведет к росту другого).

Точно также отношение к себе как нравственному человеку может вызывать у самого себя чувство гордости, которое в терминах методики «Нарциссические черты личности» и в наших статистических связях проявляет себя как «ожидание особого отношения к себе», в «грандиозном чувстве самозначимости» и в «потребности в постоянном внимании и восхищении». Но даже если у человека рождаются подобные переживания, то их можно считать достаточно естественными, т.к. природа нарциссизма по своей сути архетипична. Но еще раз, в нашей выборке лиц с выраженными признаками нарциссизма нет, а показатели самоотношения, в целом, «средины».

Так может быть явление личностной зрелости в определенной степени и состоит в умении себя сдерживать в собственных негативных проявлениях?

Продолжим ход собственных мыслей, для чего приведем несколько примеров.

1) психолог пишет заключение об установочном поведении психопатизированной личности, вскрывшей себе вены и любым способом избегающей службы в армии (но без декомпенсации он легко ее может продолжить, а в некоторых случаях и достичь высот в карьере);

2) малообразованный и имеющий в своем «арсенале» проявления девиантности (например, «не дурак выпить»), гастарбайтер прыгает на козырек подъезда и по газовой трубе взбирается в горящую квартиру и спасает ребенка на глазах зевак, парализованных ситуацией;

3) успешный в среде студентов профессор и с успехом же читающий лекции для рабочей молодежи попадает в окопы и проявляет крайне инфантильное поведение (каждый из нас не универсален и не ко всем жизненным ситуациям может быть приспособлен, и, к тому же, не каждый из нас может стать, например, водолазом или спасателем, равно как военным, летчиком и т.д.), но этот про- фессор может себя реализовать и в боевой ситуации и в качестве психолога, если он психолог или философ по образованию (и не только), в качестве военного инженера (если он, например, строитель) и т.д., но может также и с автоматом в руках встать на защиту Отечества, но может и сдаться в плен при первой возможности, пытаясь спасти свою жизнь.

Таких примеров можно привести множество, но суть приведенных в том, что в каждом случае речь едет о поступке, в котором присутствует мотивация, саморегуляция и иные проявления личности. В этой связи суть нашего вывода состоит в следующем. Выделяемые многими авторами, изучающими проблему личностной или психологической зрелости, психологические особенности «зрелой личности» и отраженные в имплицитных концепциях зрелой личности - ответственность, осознанность и рефлексивность, направленность на саморазвитие, самопринятие и самоуважение, жизнестойкость, самоуправление и организация жизни, целостность и конгруэнтность, широта связей с миром, позитивность межличностных отношений, толерантность, наличие нравственного сознания и гуманистических ценностей [3, 9 и др.], это преддиспозиции зрелости, далеко не всегда имеющие возможность себя реализовать и далеко не всегда присутствующие в перечисленном объеме в отдельном человеке.

Это «зазеркалье» зрелости: можно всю жизнь стремиться к личностному саморазвитию, проявлять чудеса жизнестойкости, но оставаться, при этом, эгоистичным мерзавцем. С одной стороны «зрелая личность» $\bigotimes$ это конструкт целостный, в котором все перечисленные личностные проявления взаимосвязаны, но с другой, как сказано в Писании, «по делам вашим да будет вам». И здесь мы полностью согласны с Е.Л. Доценко и В.А. Старцевой [5], считающими, что мерой зрелости личности может выступать только поступок, и только зрелый поступок.

Как показало наше исследование, уже умение ограничивать себя в «нелицеприятных» для «человеческой природе» явлениях (что нами и было показано в исследовании в целом, а также в установлении статической связанности между использованными в работе показателями, чем и была подтверждена 2 гипотеза исследования) уже выступает отдельными показателями зрелости, но далеко недостаточными, и в этой связи личностные дериваты психологической зрелости также еще недостаточны для ее констатации.

\section{Зак^ючение}

Личностная или психологическая зрелость может быть оценена (и реализована) лишь в конкретных жиз- 
ненных проявлениях: без «умной» любви к ребенку нельзя его вырастить психологически здоровым и вне «умной» самоотдачи партнеру по брачным отношениям легко потерять семью, нельзя себя «самоактуализировать» вне нравственного отношения к другим людям и т.д. Личностная зрелость проявляет себя в адаптивных способностях личности, понимания под адаптацией возможности задействования своих всегда несоциальных личностных резервов, но, также и в умении находить наиболее оптимальные именно для себя «ниши» жизненного присутствия, которые также будут приносить и пользу другим людям.

Все это далеко не всегда является поступком в общепризнанном понимании этого слова: здесь далеко не всегда присутствует «привычная» героика. Но главное в нашем понимании личностной зрелости - это умение удерживать себе от делания недолжного, помноженное на постоянное умение делать все необходимое и должное в каждой конкретной жизненной ситуации (позиция стоицизма: делай то, что должно и будь то, что будет).

Конечной мерой такой зрелости, на наш взгляд, выступает оценка линии жизни человека. Безусловно, мы все делаем жизненные ошибки. Но умение их анализировать (рефлексия) и потом учитывать и больше не совершать, всякий раз понимая, что «я себе этого не прощу» (и в основе такого понимания должен быть нравственный выбор), это, на наш взгляд, и есть внутренняя мера поступка, и здесь уже речь идет именно о поступке, и в основе таких жизненных выборов и поступков как и обратно связанными с ними (одно влияет на другое), безусловно, лежат и особенности нашего характера, и нашей личности в целом, перспективы развития которых так хорошо описывают имплицитные концепции личностной зрелости.

Однако без постоянной активной и нравственной включенности в реальную жизнь, в реальные социальные отношения, с постоянными делаемыми выборами и реализацией всего «добра», декларируемого такой личностью в поступках или уже в «малых» своих проявлениях и такая «зрелая личность» будет оставаться психологически мертвой.

Иначе говоря, в понимании психологической или личностной зрелости основной упор нами делается не столько на наличие у человека тех или иных личностных свойств, качеств, или проявлений, а на то, как, в чем и когда он их реализует. И если по лаконичному выражению Э. Гуссерля сознание это то, о чем мы в данный момент думаем, то личностная зрелость $\bigotimes$ незрелость - это наше поведенческое и отношенческое проявление в ответе на запрос среды (и здесь уже не только внешней, но и внутренней, многообразной, как биологической, так социальной и духовной), и, при этом, и то (сознание) и другое (личностная зрелость) - это интегративные и весьма сложные образования, у каждого из нас разные, но если сознание в первую очередь характеризуется произвольностью, то психологическая зрелось - активной жизненной включенностью, и, в первую очередь, с ориентацией на социальную нравственность.

1. Братусь Б.С. Аномалии личности. - М.: Мысль, 1988 - 302 с.

2. Грановская Р.М. Психология веры. - СПб.: Питер. 2010. - 480 с.

3. Дерманова И.Б., Манукян В.Р. Личностная зрелость: к определению психологического содержания. // Вестник Санкт-Петербургского университета. Серия 12: психология, социология, педагогика. - 2010. - №4. - С.68-73.

4. Джонсон С.М. Психотерапия характера: методическое пособие для слушателей курса «Психотерапия». - М.: Центр психологической культуры, 2001. $356 \mathrm{c}$.

5. Доценко Е.Л., Старцева В.А. Продуктивная роль поступков в обеспечении личностной зрелости. // Мир будущего и новая философия образования. Сборник научных трудов. - Калининград: БФУ им. Иммануила Канта, 2019. - С.45-53.

6. Наследов А.Д. SPSS: Компьютерный анализ данных в психологии и социальных науках. - СПб.: Питер, 2007. - 416 с.

7. Наследов А.Д. Математические методы психологического исследования. Анализ и интерпретация данных. - СПб.: Речь, 2006. - 392 с.

8. Сидоренко Е.В. Методы математической обработки в психологии. - СПб.: Речь. 2001. - 350 с.

9. Скворцова Л.Л. Индивидуально-типологические особенности имплицитных концепций личностной зрелости. // Вестник Могилевского государственного университета им. А.А. Кулешова. Серия С: психолого-педагогические науки: педагогика, психология, методика. - Могилев (Беларусь). Изд-во: МГУ им. А.А. Кулешова. - 2020. - №1(55). - С.76-83.

10. Шамшикова 0.А., Клепикова Н.М. Операционализация понятия «нарциссизм» в пределах психической нормы. // Мир науки, культуры, образования. Горно-Алтайск: Изд-во «Редакция международного научного журнала «Мир науки, культуры, образования». - 2011. - №3(28). - С.151-158.

(c) Мачуха Александр Михайлович (aleksandrinfo@bk.ru), Васильева Ольга Семеновна (vos@sfedu.ru).

Журнал «Современная наука: актуальные проблемы теории и практики» 